\title{
New Wood Applications in Architecture
}

A four metre high cobra has recently appeared at the Inffeldgasse Campus of Graz University of Technology. The cobra is an architectural experiment by researchers at the TU Graz to demonstrate the versatility of wood as a construction material in a highly impressive manner. Building the sculpture would not have been possible without the use of adhesive technology.

A renewable raw material: Austria has a rich supply of wood a valuable resource that can be used in a multitude of ways. Researchers at Graz University of Technology are convinced that it still has great potential as a construction material. "The cobra at the Campus is an architectural experiment. We want to demonstrate just how much can be achieved by using wood as a material," explained the project leader, Albert Wiltsche, from the Institute of Architecture and Media, describing the background to the snake sculpture. From works of art to houses and indus-

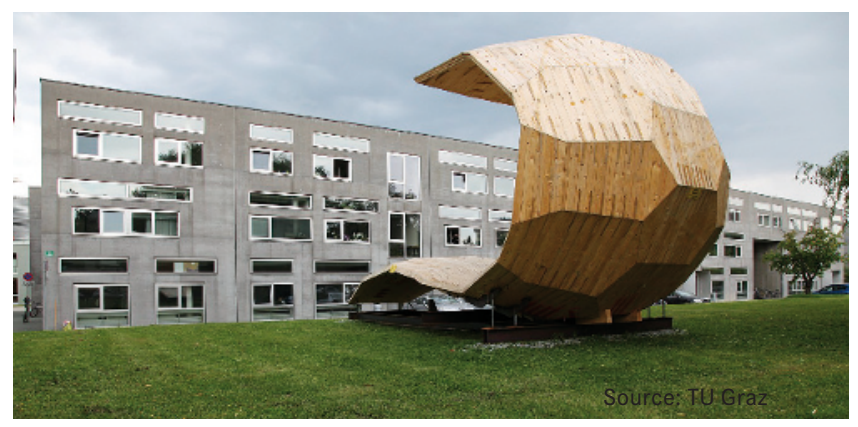

The sculpture at the Inffeldgasse Campus of Graz University of Technology impressively shows what can be achieved by using wood as a construction material with the aid of adhesive technology trial buildings: "Its range of utilisation is infinitely great, and includes various applications in architecture."

\section{Gluing instead of screwing}

"Gluing instead of screwing" was the basic principle behind this project. A special adhesive is used to hold the plywood panels together, and the individual steps have to be precisely coordinated. The necessary tests were carried out at the nearby Building Construction Centre of Graz University of Technology under the scientific leadership of Thomas Bogensberger. The Institute for Timber Engineering and Wood Technology located there is seen internationally as the "cradle" for the use of this type of plywood. Therefore, the research scientists now want to use this material, which they have played a key role in developing, for architectural applications. Other advantages of this innovation include shorter construction periods and therefore lower costs.

The research activities are part of the scientific focus on the topic of "Sustainability" at Graz University of Technology. Research in the field of sustainability - including sustainable construction is a key area of interdisciplinary scientific activity at the university.

For further information, please contact: Ass. Prof. Mag. rer. nat. Dr. techn. Albert Wiltsche, Institute of Architecture and Media,wiltsche@tugraz.at

\section{Large-Scale Production of Succinic Acid}

BASF and Purac, a subsidiary of CSM, are establishing a 50-50 joint venture for the production and sale of biobased succinic acid. Succinic acid is used, among other things, for solvents, polyurethanes and plasticizers, and is therefore an economically and ecologically attractive alternative to petrochemical raw materials.

$\mathrm{B}$ ASF and CSM have been conducting research on succinic acid under a joint development agreement since 2009. The complementary strengths of the two companies in fermentation and downstream processing led to the development of a sustainable and highly efficient manufacturing process based on a proprietary microorganism. The bacterium used is Basfia succiniciproducens, which produces succinic acid through natural processes and is capable of metabolizing a variety of renewable materials into biobased succinic acid. The new process combines high efficiency with the use of renewable raw materials and the fixation of the greenhouse gas carbon dioxide $\left(\mathrm{CO}_{2}\right)$ in the production of succinic acid. This makes biobased succinic acid an economically and ecologically attractive alternative to petrochemical raw materials.

The demand for succinic acid is anticipated to grow strongly in the years ahead, driven mainly by bioplastics, chemical intermediates, solvents, polyurethanes and plasticizers.

BASF and CSM are currently modifying an existing fermentation facility at Purac's Montmélo site near Barcelo- na, Spain, for the production of succinic acid. This plant, which will commence operations in late 2013 with an annual capacity of 10,000 metric tons of succinic acid, will put the new joint venture company in a leading position in the global marketplace. This is complemented by plans for a second large-scale facility with an annual capacity of 50,000 metric tons of succinic acid to enable the company to respond to the expected increase in demand. The final investment decision for this facility will be made following a successful market introduction. 